\title{
The Influence of e-WOM Information Characteristics on Learning Trust and e-WOM Intention Among Online Learning
}

\author{
Jeong Suk Noh, Hyeong Yu Jang, Su Sung Jeon \\ Author Dept. of Business Administration, Gyeongsang National University, \\ 501, Jinju-Daero, Jinju 660-701, South Korea \\ ${ }^{1}$ Calfs2002@hanmail.net; 2 jmgt21@gnu.ac.kr; ${ }^{3}$ jss9999@gnu.ac.kr
}

\begin{abstract}
In this study, the characteristics of e-WOM information within nonface-to-face online learning were derived to reveal its impact on online learning trust among online learners, and whether learning trust affects e-WOM. According to the purpose of this study, a survey was conducted on users who experienced non-face-to-face learning to clarify the research hypothesis, using SPSS 20.1 for reliability analysis and AMOS 21 for the collected final samples. Through the empirical analysis results of the research, it can be confirmed that consensus, vividness, and neutrality are influencing factors inducing e-WOM intention and the efficiency of online learning education promotion among online learning students. An empirical and in-depth analysis of online learning education was possible as an important information channel for users through online learning. Based on this, it is expected that use e-WOM will be a meaningful promotion of through non-face-to-face online education use of all online education institutions.
\end{abstract}

Keywords: e-WOM, consensus, vividness, neutrality, trust, e-WOM. 


\section{Introduction}

In this era of the Fourth Industrial Revolution, many online users are using information from new media such as online reviews, social network services (SNSs), blogs, and virtual communities on the Internet product before purchasing a desired product a platform called Web2.0. Many current users look for a lot of information on the Internet before purchasing a desired product (Donnavieve et al., 2005). Accordingly, information created through word-of-mouth, called product recommendations and non-recommendation opinions from consumers who have purchased products online, is becoming information that consumers search for (Chrysanthos, 2003). These words-of-mouth are statements, whether positive or negative, found on online forums and client feedback sections, which are the basis of potential consumers of a product or clients of the company (Thurau, 2004).

When a consumer looks for online word-of-mouth information, it means that they are not only looking for information from sellers or sales intermediaries about a product or service, but also reviews and evaluations of products written by other consumers. It plays an important role in the pre-preparation for consumers to reduce the risk when purchasing a certain product (Pavlou and Dimoka, 2006).

In the field of online education, studies on online word-of-mouth are also being conducted. It has been shown that online word-of-mouth information ultimately affects online purchase intentions when online users, i.e, students, decide to learn online learning. Consequently, as consumers become increasingly dependent on online word-of-mouth information, trust in online learning information is essential for consumers to utilize online oral information. In particular, just as industries in modern society experienced the Industrial Revolution with the development of information and communication technology and moved from manufacturing to service areas, the online education sector faced challenging transitions from face-toface to online classes. Especially, since there is a huge amount of information online, consensus to oral information acts as a very important information characteristic (Chiou and Cheng, 2003).

As the industry of the modern society went through the industrial revolution along with the development of information and communication technology and moved from manufacturing to the service field, online education is becoming an important field acing the challenging reality of "online non-face-to-face class". Meanwhile, the 4th Industrial Revolution and the development of information technology broke down the boundaries between industries as well as the national economy, and this phenomenon continues in the online education market (Kim, 2020).

South korea's Ministry of Education announced the guidance of emergency measures for colleges, and subsequently updated response plans according to changing circumstances. However, most domestic universities have made profound 
changes to the academic calendar, such as starting online classes only in mid-March 2020 (Ministry of Education, 2020).

Now, each university and educational institution has no choice but to prepare for classes considering these changes. The design and operation of online education classes, which are different from the sudden and embarrassing first semester, are urgently needed.

The non-face-to-face channel has been expanding in a limited area until now because it cannot provide sufficient information to consumers due to difficulty in two-way communication. In other words, online consumers are both active information seekers and producers of electronic word-of-mouth (e-WOM)(Lee, 2020).

According to this point of view, one of the topics that has received a lot of attention recently is about oral communication through online learning. Previous studies related to oral communication have brought great interest in the source of information (Charo et al., 2015; Torlak et al., 2014). But, e-WOM communication is highly likely to be influenced by an informational point of view rather than a social point of view due to its anonymity.

In 2010, internet penetration rate began to increase rapidly, enabling and activating the combination of the Internet and mobile targeting consumer users, making communication between online users faster and wider. The everyday use of the online high-speed Internet and the popularization of smart phones are promoting the spread of e-WOM intentions. As access to online learning expands due to the proportion of online learning users, e-WOM is expected to increase further.

However, since there is a difference in online learning experience and use for each person, the factors that influence the online learning trust by the characteristics of online oral information formed by consent, vividness, and neutrality were derived. The impact of online learning trust on online oral intention was studied.

Through the results of this study, we would like to present strategic implications that are helpful in the process of establishing differentiated marketing strategies for online education.

The purpose of this study is to identify important factors among the characteristics of e-WOM information, analyze how it affects learning trust, and verify the relationship between online learning trust and online word-of-mouth intention.

In order to provide online learning users with the improved education of online learning institutions, this study examines the process of creating a strategy suitable for e-WOM intention in which the e-WOM information characteristics match the learning trust unlike the existing online learning education, and through this, it is expected that online learning institutions will be able to present appropriate judgment criteria for online word of mouth information characteristics.

Based on the results of online learning institutions, it will be possible to provide 
practical implications necessary for improving the quality of online learning services and strengthening the establishment of marketing strategies.

\section{Theoretical Background and Hypothesis}

\subsection{Characteristic of Online Oral Information: Consensus, Vividness, Neutrality}

When information recipients do not know well about the information source, such as e-WOM, the trust of the information is determined by inferring from the perceived message clues (Yang et al., 2008). The reliability of e-WOM is determined by the number of consent reviews for oral information from other consumers (Bone, 1995). Offline WOM is highly reliable because it occurs between consumers who are close to each other, whereas e-WOM is more reliable if there are many posts of the same opinion after adopting a specific opinion of e-WOM because the information provider and the receiver have no relationship (Pavlou and Dimoka, 2006).

Looking at the previous studies on e-WOM information, the characteristics that are commonly handled can be divided into three parts: First, consensus, which indicates the degree to which consumers agree with a specific product. Second, vividness, which means the degree of delivering specific and detailed information about an object by using various media tools such as videos and images, away from text-oriented oral information. Third, neutrality, which refers to the degree to which the article about online information about a specific product is described in a neutral position without being biased toward the positive or negative side (Lee et al., 2013).

Consensus is expressed through views, comments, and recommendations, and is a useful tool to measure the reaction of other consumers, while vividness is when consumers directly provide empirical information increasing the reliability of information along with neutrality. Recently, the characteristics of e-WOM information can be classified in various ways such as consensus, vividness, neutrality, usefulness, flexibility, up-to-datedness, and reliability, but this study attempts to examine the characteristics of e-WOM information by consensus, vividness, and neutrality. Consensus and vividness show the basic characteristics of the reliability of the information source (John et al., 1989; Jun and Kim, 2020).

The neutrality of the message refers to the degree to which the direction of the message is not biased to one side and is described in a neutral position (Schindler and Bickart, 2005). That is, the message should be neutral and not positive or negative about the product or service (Yoo, 2017). Therefore, this paper intends to conduct a study based on the characteristics of online oral information including consensus, vividness, and neutrality.

\subsubsection{Consensus}

Consensus is expressed through views, comments, and recommendations, and is a 
useful tool for measuring the reactions of other consumers. Online word of mouth is characterized by low credibility as it is formed from people with no ties at all. Therefore, the reliability of online word of mouth should be understood differently from offline word of mouth (Brown et al., 2007). That is, in offline word-of-mouth, trust in the information provider can become trust in information, but in online word-of-mouth, there is trust in the information itself because there is no information about the information provider. Therefore, the characteristics of wordof-mouth information play an important role in securing its reliability and the most important factor is consensus. In the consumer decision-making process, vivid information has more appeal to consumers than information that is not, and is more likely to be stored in memory for a long time.

Consensus of information in e-WOM refers to the degree to which two or more people agree on product performance (Weiner, 2000). In a study on consumer assimilation behavior, it was said that the product evaluation of other consumers affects the consumer's product judgment (Chiou and Cheng, 2003) and explained that the intensity of consent increases when opinions supported by others are added (Bone, 1995).

\section{H1 The consensus of the characteristics of e-WOM information will have a positive effect on trust.}

\subsubsection{Vividness}

The vividness of WOM information means that when oral information is provided, the information is presented so that the information recipient feels realistic about the service or product (Nessim and Wozniak, 2001).

In the consumer decision-making process, vivid information has more appeal to consumers than information that is not, and is more likely to be stored in memory for a long time (River, 2004).

Sundar and Kalyanaraman (Sundar and Sriram, 2004) also found that vivid word of mouth information with very specific content and actual experience increases the reliability of the recipient. In general, when positive information and negative information are provided together, rather than positive or negative information, the reliability of the information is rather increased.

The reason why oral communication is more effective than other means of promotion is that consumers who have experienced a product or service use a variety of media to deliver it lively. The vividness of the oral information presented can be defined as the message being emotional, entertaining, or clear and imaginative. In a study by Schindler and Barbara (Schindler and Barbara, 2005), it was found that vivid oral information, which is very specific and that seems to have actually been experienced, increases the reliability of the recipient.

H2 The vividness of the characteristics of e-WOM information will have a positive effect on trust. 


\subsubsection{Neutrality}

Among the characteristics of word-of-mouth information, neutrality refers to the degree to which the direction (negative/positive) of word of mouth message is not biased to one side and is described from a neutral standpoint. The message of neutral direction is not biased, and the credibility of the source is perceived as higher than that of the message.

The message should be described in a neutral way, not positive or negative about the product or service. Therefore, in this study, the characteristics of e-WOM information are composed of consensus, vividness, and neutrality Rather than providing positive or negative information individually, providing them together increases the reliability of the information (Martin, 2006).

The e-WOM information said that neutral information in a mixed state being of positive and negative is more reliable than content that is skewed to one side (Doney and Joseph, 1997). said that a message that presents both positive and negative information increases public confidence by reducing the negative perception of the recipient. Based on the preceding studies above, the hypothesis was established as follows.

\section{H3 The neutrality of the characteristics of e-WOM information will have a positive effect on trust.}

\subsubsection{Online Learning Trust and e-WOM}

In this study, learning trust is defined as the degree of belief that the brand of products provided on the online education site will strive to provide excellent products or services to customers (Aaker, 1997). In order to measure the online learning reliability, the measurement items were modified and used according to this study by referring to the study of The e-WOM communication is word-ofmouth communication developed through the Internet, and when WOM is delivered on the Internet, it is called online word-of-mouth or electronic Word-of-Mouth(eWOM) (Patrali, 2001). In other words, it is the exchange of information such as product information, use experience, and recommendations that occur between consumers through the Internet (Sridhar and Vijay, 2001).

In online, consumers are a kind of channel that enables companies and e-WOM to interact to communicate with third-party consumers. Word of mouth recommended to others is considered a source of information as the most influential cause before purchase. Online customer loyalty is created by satisfaction with online providers, and ultimately, revisiting word of mouth intention can lead to actions. Users who have difficulty in direct experience with products and services prior to purchase will first search for word-of-mouth or online word-of-mouth on websites for decision-making.

Therefore, users who experience the service of the supplier due to positive word of mouth online are more likely to make a positive cognitive evaluation of the service quality of the company and supplier. As such, e-WOM, which is active as a 
means of satisfying the user's value, spreads quickly and easily through the Internet and has a considerable impact, as a result, it is regarded as a communication channel that marketers must manage as the top priority today.

Web 2.0 created an easy environment in which online word-of-mouth creation and delivery can be continuously performed. e-WOM is an informal communication with the possibility of using a product or service and recommending a product or service to others According to the study of Babić Rosario et al, online information acquisition can lead to a willingness for positive word-of-mouth about the (Rosario et al., 2016).

Therefore, in this study, under the assumption that higher learning trust has a positive effect on e-WOM intention, the following hypothesis is to be established.

A study on online bookstores also found that consumer reviews increased book sales. This can be seen that the acceptance of WOM information increases purchase intention and is linked to actual purchase behavior. Based on the preceding studies, the following hypothesis was established (Chevalier and Mayzlin, 2016).

H4 The higher the online learning trust, the more the positive effect on eWOM intention.

\section{Research Model and Method}

\subsection{Research Model}

In this study, by modifying existing studies to measure the relationship between variables, we intend to examine the influence of e-WOM information characteristics on online learners' learning trust and e-WOM intentions. Vividness, the characteristic of e-WOM, according to Nisbett and Ross, influences trust (Nisbett and Lee, 1980; Silke and Mangold, 2011; Marie, 2002; Reza and Samiei, 2012; Jingen et al., 2018) and a prior study showing that online trust influences word of mouth intention (Abdullah et al., 2015; Charo et al. ,2015; Gunther, 1992; Wu and Wang, 2011). In this study, in order to measure the relationship between variables, previous studies were modified, and measured on the seven-point likert scale. Based on this, the research model was set up by modifying and using the measurement items appropriately for this study.

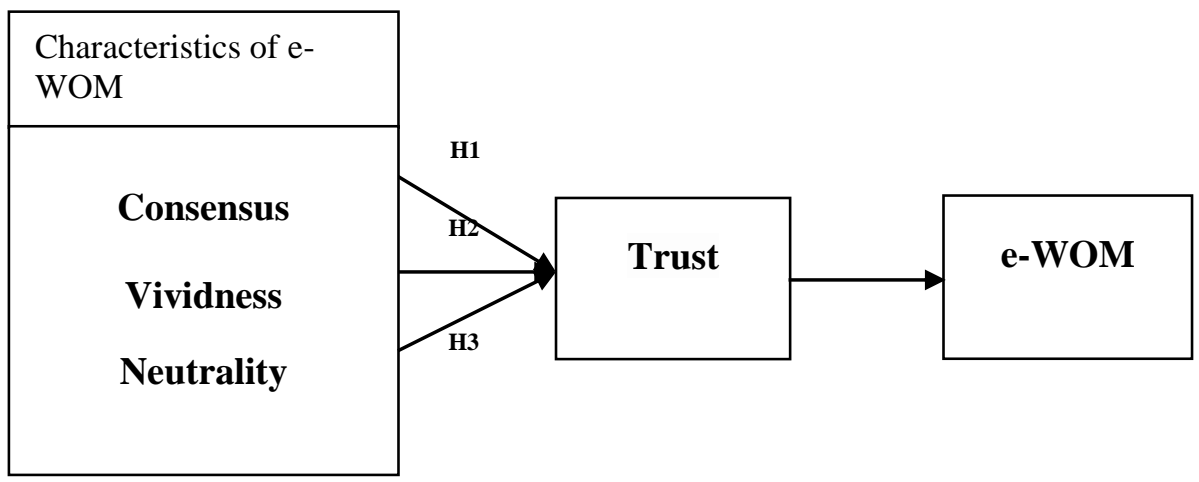

Fig. 1: The research model 


\subsection{Research Methods}

In this study, a statistical analysis technique as used in consideration of the overall characteristics of the sample, such as the number of variables, the nature of the analysis, and the type of scale, in order to derive accurate results before performing the reliability and validity verification of variables and hypothesis testing. That is, the measurement scale was evaluated through exploratory factor analysis and reliability verification of the multi-item scale of attributes within the factor category through the scale purification process prior to testing the research hypothesis. First, a frequency analysis was performed to find out the general characteristics of the sample. Second, as a preliminary step for the analysis of the research hypothesis, exploratory factor analysis was performed using the SPSS 21.0 statistical package on the measured variables extracted by examining previous studies, and then the reliability of each factor was verified. In reliability verification, the Cronbach's $\alpha$ value was referenced to eliminate the question that hindered the overall reliability.

There are five configurations in this study with multiple items measured using a seven-point likert type scale ( $1=$ very disagree, $7=$ very agree $)$. A total of 250 college students and ordinary people with experience using online learning were sampled by convenient sampling. For data collection, a persona interview technique was used in Gyeongnam-do from March 1 to March 10, 2021, and 242 students were extracted as a final sample, removing 8 questionnaires due to missing data. Structural Equation Modeling (SEM) was performed using moment structure analysis (AMOS) to test the correlation between the effect of the proposed online word of mouth information on learning trust and online word of mouth intention (eWOM). By examining the causal relationship between the concepts of the model through SEM and testing the model against the measured data obtained, we were able to confirm how well the proposed model fits the data (Hair et al., 2006). The analysis was used for AMOS 20.0 and SPSS 21.0.

\subsection{Operational Definition of a Variable}

Based on the measurement items of each variable the operational definitions and measurement items of each variable verified in previous studies were used. In order to secure the validity of this measurement scale, the validity and suitability of the contents were reviewed based on the relevant experts prior to this investigation. In addition, the questionnaire was constructed in accordance with the purpose of this study, centering on the questions that have proven the reliability and validity of the questionnaire in previous studies. [Table 1] is a measurement of variables and authors. 
Table 1: Measurement of variables and author

\begin{tabular}{|c|c|c|}
\hline & Measures / 7Likert-type scale & Authors \\
\hline $\begin{array}{l}\text { Consen- } \\
\text { sus }\end{array}$ & $\begin{array}{l}\text { The degree to which two or more users present opinions that } \\
\text { agree to oral information on product performance. } \\
\text { 1. Online learning information (consensus) receive a lot of views. } \\
\text { 2. There are many recommenders for online learning information } \\
\text { (consensus). } \\
\text { 3. There are many comments on the online learning information } \\
\text { (consensus). }\end{array}$ & $\begin{array}{l}\text { Elliott } \\
\text { (Bone, } \\
\text { 1995) } \\
\text { (Chiou } \\
\text { and } \\
\text { Cheng, } \\
\text { 2003) }\end{array}$ \\
\hline Vividness & $\begin{array}{l}\text { The degree to which oral information feels concretely as if it was } \\
\text { actually experienced. } \\
\text { 1.The vividness feels like I have actually experienced it. } \\
\text { 2.The vividness is conveyed vividly by attaching a photo or } \\
\text { video. } \\
\text { 3.The vividness is specifically presented through online learning. }\end{array}$ & $\begin{array}{c}\text { (Schindel } \\
\text { er and } \\
\text { Bickart, } \\
2005)\end{array}$ \\
\hline $\begin{array}{c}\text { Neutrali- } \\
\text { ty }\end{array}$ & $\begin{array}{l}\text { The degree to which the direction of the message is described in } \\
\text { a neutral position rather than biased to one side. } \\
\text { 1. Neutrality is presented with both advantages and } \\
\text { disadvantages. } \\
\text { 2. It is presented in a neutral position. } \\
\text { 3. From a neutral standpoint, they do not focus on learning in one } \\
\text { direction of positive and negative. }\end{array}$ & $\begin{array}{c}\text { (Kang et } \\
\text { al., } \\
\text { 2017) }\end{array}$ \\
\hline Trustt & $\begin{array}{l}\text { Subjective evaluation feels reliable because oral information is } \\
\text { objective and factual } \\
\text {. The content of online learning information is generally } \\
\text { specialized. } \\
\text {. The content of online learning information is generally } \\
\text { objectively described. } \\
\text { The content of online learning information is generally reliable. }\end{array}$ & $\begin{array}{l}\text { (Li and } \\
\text { Chang, } \\
\text { 2016) }\end{array}$ \\
\hline e-WOM & $\begin{array}{l}\text { Willingness to deliver e-WOM information to other consumers } \\
\text { 1. I would like to recommend the e-WOM information that I have } \\
\text { read to others. } \\
\text { 2. I want to share the e-WOM information I read with others. } \\
\text { 3. I would like to recommend the e-WOM information I read to } \\
\text { others. }\end{array}$ & $\begin{array}{l}\text { (Raffael } \\
\text { e and } \\
\text { McLeay } \\
\text {,2014) }\end{array}$ \\
\hline
\end{tabular}

\section{Empirical Analysis Results}

Examination of demographic characteristics indicates the respondent to be $49 \%$ female and $51 \%$ male. In terms of the age distribution, $64 \%$ of the responders was in the 20s, which might be a limitation of this study. For the purpose of using online 
learning, 42\% answered because of certificates they obtain and $30 \%$ because of learning in various fields. In terms of hours in online learning, 30\% answered 10 to 7 hours per day, 51\% answered 7 to 5 hours per day, and 19\% answered others In this study, Cronbach's $\alpha$ value was used to verify the reliability of the measurement items, and factor analysis was performed to verify the concentration validity within factors and the discriminant validity between factors. Factor analysis was carried out by principal component analysis, and in order to secure the independence of the factors, it was rotated using the Varimax method.

Assessment of the measurement model involves evaluations of reliability, convergent validity, and discriminant validity of the construct measures. Generally, if the factor loading of each measurement item onto its construct is more than 0.7 , the measurement item is considered valid.

Factor loadings of more than 0.7 for each measurement item indicate the convergent validity, as seen in [Table 2].

The discriminant validity was also assessed by comparing the AVE with the squared correlations between constructs. All of the squared correlations between the two constructs were less than the AVEs, which suggest that the constructs were distinct .

Table 2: Confirmatory factor analysis

\begin{tabular}{|c|c|c|c|c|c|c|c|}
\hline & Items & Std. R & S.E. & t-value & $\alpha$ & C.R & AVE \\
\hline \multirow{4}{*}{ Consensus } & 1 & .898 & - & - & \multirow{4}{*}{.897} & \multirow{4}{*}{.879} & \multirow{4}{*}{.710} \\
\hline & 2 & .776 & .052 & 16.075 & & & \\
\hline & 3 & .848 & .049 & 19.041 & & & \\
\hline & 4 & .884 & .050 & 20.902 & & & \\
\hline \multirow{3}{*}{ Vividness } & 1 & .890 & - & & \multirow{3}{*}{.930} & \multirow{3}{*}{.905} & \multirow{3}{*}{.763} \\
\hline & 2 & .951 & .057 & 20.477 & & & \\
\hline & 3 & .770 & .055 & 15.031 & & & \\
\hline \multirow{3}{*}{ Neutrality } & 1 & .899 & - & - & \multirow{3}{*}{.910} & \multirow{3}{*}{.922} & \multirow{3}{*}{.798} \\
\hline & 2 & .902 & .057 & 20.390 & & & \\
\hline & 3 & .879 & .063 & 19.668 & & & \\
\hline \multirow{3}{*}{ Trust } & 1 & .875 & - & - & \multirow{3}{*}{.860} & \multirow{3}{*}{.855} & \multirow{3}{*}{.686} \\
\hline & 2 & .852 & .052 & 14.321 & & & \\
\hline & 3 & .754 & .065 & 12.208 & & & \\
\hline \multirow{3}{*}{ e-WOM } & 1 & .864 & - & - & \multirow{3}{*}{.886} & \multirow{3}{*}{.883} & \multirow{3}{*}{.716} \\
\hline & 2 & .881 & .061 & 15.614 & & & \\
\hline & 3 & .791 & .066 & 13.351 & & & \\
\hline \multicolumn{8}{|c|}{$\begin{array}{l}\text { Model Fit Indices: } \chi 2=1358.920 \mathrm{df}=138, \mathrm{p}=0.000, \mathrm{CMIN} / \mathrm{DF}=3.542, \mathrm{GFI}=0.920 \text {, } \\
\mathrm{AGFI}=0.945, \mathrm{IFI}=0.977, \mathrm{RMR}=0.02, \mathrm{TLI}=0.947, \mathrm{CFI}=0.975, \mathrm{R} M \mathrm{SE}=0.049\end{array}$} \\
\hline
\end{tabular}


Table 3: Correlation matrix with the square root of AVE diagonally

\begin{tabular}{|c|c|c|c|c|c|}
\hline & $\mathbf{1}$ & $\mathbf{2}$ & $\mathbf{3}$ & $\mathbf{4}$ & $\mathbf{5}$ \\
\hline Consensus & .710 & & & & \\
\hline Vividness & .176 & .763 & & & \\
\hline Neutrality & .336 & .435 & .798 & & \\
\hline Trust & .462 & .240 & 504 & .686 & \\
\hline e-WOM & .270 & .624 & .396 & .211 & .716 \\
\hline
\end{tabular}

Analysis of hypotheses $\mathrm{H} 1, \mathrm{H} 2$, and $\mathrm{H} 3$ showed that online oral information characteristics consensus, vividness, and neutrality have a positive effect on trust.

Furthermore, as stated in hypothesis H4, the higher the online learning trust, the more the e-WOM intention has a positive effect. The structural model created indicated acceptable goodness-of-fit-measures $(\chi 2=1358.920 \mathrm{df}=138, \mathrm{p}=0.000$, $\mathrm{GFI}=0.920, \mathrm{AGFI}=0.942, \mathrm{RMR}=0.02, \mathrm{TLI}=0.947, \mathrm{CFI}=0.975, \mathrm{RMSEA}=0.049$ ).

The consensus of the characteristics of e-WOM information will have a positive effect on trust $(\mathrm{H} 1=0.567 / \mathrm{t}=6.75$ and $\mathrm{H} 2=0.089 / \mathrm{t}=1.92)$. The vividness of the characteristics of e-WOM information will have a positive effect on trust. The neutrality of the characteristics of e-WOM information will have a positive effect on trust $(\mathrm{H} 3=-0.606 / \mathrm{t}=7.17)$. The consensus of the characteristics of $e-W O M$ information will have a positive effect on trust $(\mathrm{H} 4=0.858 / \mathrm{t}=13.30)$.

Table 4: Results of hypothesis testing

\begin{tabular}{|c|c|c|c|c|c|c|}
\hline \multicolumn{2}{|c|}{ Hypotheses Tests } & Std. R & S.E. & t-value & p-value & Result \\
\hline H1 & $\begin{array}{c}\text { Consensus } \rightarrow \\
\text { Trust }\end{array}$ & .567 & .113 & 6.75 & $* * *$ & Accepted \\
\hline H2 & $\begin{array}{c}\text { Vividness } \rightarrow \\
\text { Trust }\end{array}$ & .089 & .055 & 1.92 & $* * *$ & Accepted \\
\hline H3 & Neutrality $\rightarrow$ Trust & .606 & .086 & 7.17 & $* * *$ & Accepted \\
\hline H4 & Trust $\rightarrow$ e-WOM & .858 & .079 & 13.30 & $* * *$ & Accepted \\
\hline
\end{tabular}

\section{Conclusions}

In the era of information technology development according to the development of the 4th industrial revolution technology, learning information generated in the online space spreads to other people easier and quicker, and companies use the information created by consumers as their marketing tools. So, there is a need to better understand the information sharing or online diffusion process ( $\mathrm{Li}$ et al., 2017). It is an important marketing tool that must be managed in future online learning institutions and all educational institutions. Recently, as purchasing activity online increases the influence of e-WOM information is expanding by actively posting user reviews and evaluations rather than just purchasing activities. This 
study analyzed he effect of e-WOM information characteristics among online learning institutions on learning trust and the effect of online learning trust on eWOM intention. In order to achieve the research purpose, consumers who have experienced actual purchasing decisions at online learning institutions were surveyed. A total of 242 copies were used for empirical analysis. It can be seen that when trust in e-WOM information is high, as the online word of mouth intention increases, the willingness to recommend to others increases, and at the same time, the intention to purchase the corresponding online learning product also increases. Furtheromor it can be seen that the more positive the online learning trust is, the eWOM intention spreads and the purchase intention also increases. Based on previous studies, the effect of online trust, a constituent factor of research variables on the characteristics of e-WOM information, on e-WOM intentions was verified. As a result of hypothesis verification, it was found that the characteristics of eWOM information such as consensus, vividness, and neutrality had a positive effect on the online trust of recipients of e-WOM information, and learning trust through online had a positive effect on e-WOM intention. In other words, it was found that the higher the learning reliability in the e-WOM information, the higher the e-WOM information, and the behaviors to convey or recommend to online users increase. This study draws theoretical implications providing the rationale for users of online education that will expand in the future, and revealing that the characteristics of online word-of-mouth information such as consent, vividness, and neutrality affect online learning trust and lead to the intention of online word-of-mouth (eWOM).Several important facts were discovered through the empirical results of this study.First, it was found that consensus, vividness, and neutrality, which are factors of e-WOM information characteristics, have a positive effect on online learning trust in the online learning situation. Second, it was found that trust in online learning had a positive effect on e-WOM intention.

This study provides useful data for establishing marketing strategies of online educational institutions by empirically identifying the influence of positive and negative e-WOM. Nevertheless, this study has several limitations as follows. In this questionnaire, only certain online subjects can be evaluated to induce positive online narratives.Each online learner may have a slight difference depending on the subject they take, so they will not be able to reach the same conclusion. Therefore, it is necessary to overcome these limitations in the future and to carry out research that can achieve various results through in-depth research related to offline subject evaluation by online educational institutions. 


\section{References}

Aaker, J. L. (1997). Dimensions of brand personality. Journal of marketing research 34.3 (1997): 347-356.

Abdullah, A., Iyer, P., \& Paswan, A. (2015). Personal level antecedents of eWOM and purchase intention, on social networking sites. Journal of Customer Behaviour 14.2 (2015): 107-125.

Bone, P. F. (1995). Word-of-mouth effects on short-term and long-term product judgments. Journal of business research 32.3 (1995): 213-223.

Bone, P. F. (1995). Word-of-mouth effects on short-term and long-term product judgments. Journal of business research 32.3 (1995): 213-223.

Brown, J., Amanda J. B., \& Lee, N.(2007). Word of mouth communication within online communities: Conceptualizing the online social network. Journal of interactive marketing 21.3 (2007): 2-20.

Charo, $\mathrm{N}$ et al. (2015). Determining the impact of ewom on brand image and purchase intention through adoption of online opinions. International Journal of Humanities and Management Sciences. 3.1 (2015): 41-46.

Charo, N., et al. (2015). "Determining the impact of ewom on brand image and purchase intention through adoption of online opinions. International Journal of Humanities and Management Sciences 3.1 (2015): 41-46.

Chevalier, J. A., \& Mayzlin, D. (2006). The effect of word of mouth on sales: Online book reviews. Journal of marketing research 43.3 (2006): 345-354.

Chiou, J. S., \& Cheng, C. (2003). Should a company have message boards on its web sites?. Journal of Interactive Marketing 17.3 (2003): 50-61.

Chiou, J. S., \& Cheng, C. (2003). Should a company have message boards on its web sites?. Journal of Interactive Marketing 17.3 (2003): 50-61..

Chrysanthos, D. (2003). The digitization of word of mouth: Promise and challenges of online feedback mechanisms. Management science 49.10 (2003): 1407-1424.

Doney, P. M., \& Joseph, P. C. (1997). An examination of the nature of trust in buyer-seller relationships. Journal of marketing 61.2 (1997): 35-51. 
Donnavieve, S., Menon, S., \& Sivakumar, K. (2005). Online peer and editorial recommendations, trust, and choice in virtual markets. Journal of interactive marketing 19.3 (2005): 15-37.

Gunther, A. C. (1992). Biased press or biased public? Attitudes toward media coverage of social groups. Public opinion quarterly 56.2 (1992): 147-167.

Hair, J. F., et al. (2006). Multivariate data analysis . Uppersaddle River.

Jingen, L. L., Choi, H. S., \& Joppe, M. (2018). Understanding repurchase intention of Airbnb consumers: perceived authenticity, electronic word-of-mouth, and price sensitivity. Journal of Travel \& Tourism Marketing 35.1 (2018): 73-89.

John, D., Romer, D., \& McQueen, J. (1989). Using drama to persuade. Journal of Consumer research 16.3 (1989): 335-343.

Jun, S. Y., \& Kim, K. H. (2012). The Influence of Two-sided WOM on ConsumersBrand Attitudes in an Online Context. Korea Marketing Review 27.1 (2012): 45-66.

Kang, J. W., Park, S. Y., \& Ko, J. Y. (2017). A Study on The Impacts of e-WOM Information Characteristics on Perceived Risk, Perceived Benefit and WOM Effect in Wine industry. Korean Journal of Hospitality and Tourism 26.2 (2017): 98-1.

Kim, S. M. (2020). Analysis of press articles in Korean media on online education related to COVID-19. Journal of Digital Contents Society 21.6 (2020): 1091-1100.

Lee, B. K. (2020). A study on learners' response to online college English class as general education due to the COVID-19 pandemic. Korean Journal of General Education 14.4 (2020): 97-112.

Lee, C. S., et al. (2013). The effect of WOM's information characteristics on WOM adoption in the online shopping context: Focused on the mediating roles of trust and usefulness. KOREAIDMA 16.3 (2013): 59-75.

Li, C. H., \& Chang, C. M. (2016). The influence of trust and perceived playfulness on the relationship commitment of hospitality online social network-moderating effects of gender. International Journal of Contemporary Hospitality Management 28.5 (2016): 924-944. 
Li, G. P., Hou, Y., \& Wu, A. Z. (2017). Fourth Industrial Revolution: technological drivers, impacts and coping methods. Chinese Geographical Science 27.4 (2017): 626-637.

Marie, L. K. (2002). Understanding consumer-to-consumer influence on the web. Duke University, 2002.

Martin, E. (2006). Eisend, Two-sided advertising: A meta-analysis. International Journal of Research in Marketing 23.2 (2006): 187-198.

Ministry of Education. (2020). Reinforcement of response, such as pre-inspection of the response posture of educational institutions to prevent COVID-19. Retrieved fromhttps://www.moe.go.kr/boardCnts/view.do?boardID=294\&boardSeq=79572 \&l $e v=0 \& m=02$.

Nessim, H., \& Wozniak, R. (2001). Consumer behavior: An applied approach. Diss. Univerza v Mariboru, Ekonomsko-poslovna fakulteta, 2001.

Nisbett, R. E., \& Lee, R. (1980). Human inference: Strategies and shortcomings of social judgment.

Patrali, C. (2001). Online Reviews Do Consumers Use Them? ACR 2001 Proceedings, eds. M. C. Gilly and J. Myers-Levy, Provo, UT: Association for Consumer Research, (2001): 129-134.

Pavlou, P. A., \& Dimoka, A. (2006). The nature and role of feedback text comments in online marketplaces: Implications for trust building, price premiums, and seller differentiation. Information Systems Research 17.4 (2006): 392-414.

Pavlou, P. A., \& Dimoka, A. (2006).The nature and role of feedback text comments in online marketplaces: Implications for trust building, price premiums, and seller differentiation. Information Systems Research, 17.4, (2006): 392-414.

Raffaele, F., \& McLeay, F. (2014). E-WOM and accommodation: An analysis of the factors that influence travelers' adoption of information from online reviews. Journal of travel research 53.1 (2014): 44-57.

Reza, j. m., \& Samiei, N. (2012). The impact of electronic word of mouth on a tourism destination choice: Testing the theory of planned behavior (TPB). Internet Research. Electronic Networking Applications and Policy, 22.5 (2012): 591-612. 
River, N. J. (2004). Prentice-Hall. Sundar, S. Shyam, and Sriram Kalyanaraman. "Arousal, memory, and impression-formation effects of animation speed in web advertising. Journal of Advertising 33.1 (2004): 7-17.

Rosario, B., et al. (2016). The effect of electronic word of mouth on sales: A metaanalytic review of platform, product, and metric factors. Journal of Marketing Research 53.3 (2016): 297-318.

Schindler, R. M., \& Barbara, B. (2005). Published word of mouth: Referable, consumer-generated information on the Internet. Online consumer psychology: Understanding and influencing consumer behavior in the virtual world 32 (2005): 35-61.

Schindler, R. M., \& Bickart, B. (2005). Published word of mouth: Referable, consumer-generated information on the Internet. Online consumer psychology: Understanding and influencing consumer behavior in the virtual world 32 (2005): 35-61.

Silke, B. S., \& Mangold, S. (2011). Brand equity dilution through negative online word-of-mouth communication. Journal of retailing and consumer services 18.1 (2011): 38-45.

Sridhar, B., \& Vijay, M. (2001). The economic leverage of the virtual community. International journal of electronic commerce 5.3 (2001): 103-138.

Sundar, S., \& Sriram, K. (2004). Arousal, memory, and impression-formation effects of animation speed in web advertising. Journal of Advertising 33.1 (2004): 7-17.

Thurau, H. (2004). Electronic word-of-mouth via consumer-opinion platforms: what motivates consumers to articulate themselves on the internet? Journal of interactive marketing 18.1 (2004): 38-52.

Torlak, O., Ozkara, B. Y., Tiltay, M. A., Cengiz, H., \& Dulger, M. F. (2014).The effect of electronic word of mouth on brand image and purchase intention: An application concerning cell phone brands for youth consumers in Turkey. Journal of Marketing Development and Competitiveness 8.2 (2014): 61-68.

Weiner, B. (2000). Attributional thoughts about consumer behavior. Journal of Consumer research 27.3 (2000): 382-387. 
Wu, P. C. S., \& Wang, C. Y. (2011). The influences of electronic word - of - mouth message appeal and message source credibility on brand attitude. Asia Pacific Journal of Marketing and Logistics 23.4 (2011): 448-472.

Yang, S. S., Hyang J. H., \& Choi, B. K. (2008). Word-of-Mouth Effect of the Electronic Tourism Information. Journal of Tourism Sciences 32.2 (2008): 109-130.

Yoo, Y. H. (2017). The impact of customer value on customer satisfaction and customer loyalty in hotel firms. Tourism Research. 42.3 (2017): 141-158. 